\title{
The Study of Animal Products Perceived Quality Based on Cue Theory- —Data from Fu Jian Province
}

\author{
Chao Zhang \\ Professor, Research Associate, Agricultural Information \\ Institute, Chinese Academy of Agricultural \\ Sciences, Beijing 100081, P. R .China/Key \\ Laboratory of Digital Agricultural Early- \\ Warning Technology, Ministry of \\ Agriculture, Beijing 100081, P. R .China \\ Ganqiong Li
}

Associate Professor, Agricultural Information Institute,

Chinese Academy of Agricultural Sciences,

Beijing 100081, P. R .China/Key

Laboratory of Digital Agricultural Early-

Warning Technology, Ministry of

Agriculture, Beijing 100081, P. R .China

\section{Zhemin Li}

\author{
Xiaoxia Dong \\ Associate Professor, Agricultural Information Institute, \\ Chinese Academy of Agricultural Sciences, \\ Beijing 100081, P. R .China/Key \\ Laboratory of Digital Agricultural Early- \\ Warning Technology, Ministry of \\ Agriculture, Beijing 100081, P. R .China \\ Yumei Zhang \\ Associate Professor, Agricultural Information Institute, \\ Chinese Academy of Agricultural Sciences, \\ Beijing 100081, P. R .China/Key \\ Laboratory of Digital Agricultural Early- \\ Warning Technology, Ministry of \\ Agriculture, Beijing 100081, P. R .China
}

Agricultural Information Institute, Chinese Academy of Agricultural Sciences, Beijing 100081, P. R .China/Key Laboratory of Digital Agricultural Early-Warning Technology, Ministry of Agriculture, Beijing 100081, P. R .China

\begin{abstract}
Currently, with the animal product quality and safety incidents frequent occurrence, food quality and safety suffered serious doubt. This paper chooses consumers in Fujian Province markets as samples, administrative divisions as the principle of sample selected, and 918 consumers in Fu Zhou, Long Yan, Nan An, Quan Zhou, San Ming, Zhang Zhou etc, six cities as study objects. And study judgment basis on animal products consumer perceived quality based on cue theory, explore personal attributes' influences on animal products consumer quality. The result shows that: color, cutting, packaging, the level of fat, marbling, PH value, price, brand, drug residues, origin certification, production date, catching season, cold chain distribution, purchase options, payment mechanisms, the last time buying experience etc, 16 quality cues can classified as five dimensions-store image, brand quality, processing, intuitive cognition and physical properties, and are basis for consumers to judge animal products consumer perceived quality. Personal attributes have a significant difference
\end{abstract}

on the five dimensions, including gender, age, household type, education background.

Keywords:consumer perceived quality; animal products; cue theory; factor analysis; differences in characteristics

\section{INTRODUCTION}

Olson and Jacoby considered that perceived quality was evaluation and judgment of products quality ${ }^{[1]}$. Consumer perceived quality is divided into subjective cognitive quality and objective evaluation quality. Objective evaluation quality was not included biased evaluation, which is towards the elements of performance, durability, design and safety by expert or producer ${ }^{[2]}$, and could accurately reactive or measure the superiority of some predetermined ideal standard level ${ }^{[3]}$. Subjective cognitive quality was products evaluation by consumers during reactive consumer process. Because consumers did not have professions on products by expert or professional producers, their perception is subjective, can hardly form the objective 
measure standard. The main reason for the formation of perceived quality was because of asymmetric information, compared to the producer, the consumer was difficult to fully and accurately understand the product information in the purchase of the game activity in weak position, when the more complex products, the quality of products judged by the naked eye would beinaccurate. COX proposed using product quality cues to study consumer perceived quality. He defined the cue as information, and believed that products consumer perceived quality was a perceived set of consumer perceived quality of products with various attributes ${ }^{[4]}$.Quality cue was that consumers would be able to be aware of before consumption activities, and quality attributes before consumption imperceptible, therefore, in the case of asymmetric information, consumers could rely on the corresponding cues to estimate the quality of products ${ }^{[5-6]}$. Consumers firstly discriminated the substitution index of product quality, and after comprehensive considered in a number of independent cues, finally formed products consumer perceived quality.

Cue theory in the study of products perceived quality gradually becomes rich. Grunertet al provided a more complete perspective of food quality model based on cues theory, because the intrinsic properties of food lead consumers to judge its quality before buying mainly based on available cues ${ }^{[7]}$. Bricmont and laval used extrinsic cues, such as: brand and packaging to study consumer perceived quality of Belgium coffee. The study found that cues had influences on Belgium coffee perceived quality and different cues interact and together affect consumer perceived quality on coffee. Bredahl aimed at brand beef, studied the relationship between extrinsic cues and perceived quality ${ }^{[8]}$. Renee Kim using Japanese mainland consumers as a sample, studied the relationship between extrinsic cues and their food consumer perceived quality. The results showed that country of origin is an important factor which affected consumer perceived quality judgment ${ }^{[9]}$.Domestic scholars from brand, price and country of origin and other extrinsic cues, studied consumer inferring related cues of product quality, explored its influences on consumer purchase intentions and optional path. The empirical results showed that, with Western brands, as well as U.S. origin and high price, products would get more accessible consumer perceived quality ${ }^{[10-11]}$. Wang Jun on the basis of previous studies, researched on the relationship between extrinsic quality cues, such as agricultural brand, price, country of origin, packaging, certification mark, supermarkets, and perceived quality. The results showed that agricultural product extrinsic quality cues had a significant positive correlation with perceived quality, in which brand, packaging and certification marks highly correlated; price and country of origin moderate correlated; supermarket image low correlated.Hu haitao, based on the relevant literature at home and abroad ,chose northeast rice as an object, formed a rice consumer perceived quality scale consisting of eight extrinsic cues ,such as :packaging, certification logo, store image, reputation, price and brand to develop empirical research. The survey results from Chong Qing and $\mathrm{Hu}$ Bei showed that certification logo, store brand, reputation, price and brand all had remarkable effect, in which packaging, certification logo and store image were slight strong, and perceived quality had a significant positive effect on purchase intention.

Currently, the quantity of cue theory researches on agricultural products consumer perceived quality has increased at home and abroad. But mainly focus on extrinsic cues generally, fewer intrinsic cues. Specific to the breed, animal products rarely involved. Domestic animal products manufacturing and marketing modes, such as branding, packaging, quality certification and other extrinsic cues are difficult to fully reflect animal products consumer perceived quality. 


\section{RESEARCH METHODS AND DATA SOURCES}

\section{Likert 5 scale measurement design}

Likert scale is a psychological reaction scale most widely used in survey research, which is made by American social psychologist Rensis Likert in 1932, based on the summated rating scales. The five is the most widely used scale ,respectively on the behalf of "strongly disagree", "disagree", "not necessarily", "agree" strongly agree ", were recorded as 1,2,3,4,5, reflecting the extent of the respondents agreed to ask specific items. Animal products belong to the category of food, therefore, based on a wide theoretical literature about the cues, drawing on experts and scholars developed, modified food choices motivation Scale and related studies, combined with Chinese residents' consumption characteristics of animal products and cooking habits, develop a perceived quality of animal products consumption questionnaire consisting of two parts. The first part is socio-economic characteristics of consumers, including age, gender, education, income and other individual characteristics information; the second part is measurement table for animal products consumer perceived quality, containing 16 measurements, using Likert scale to measure them.

\section{Data analysis methods}

This paper uses 16 cues to measure the perceived quality of animal products. Many variables, interfering with each other, so that people cannot understand the influences on animal products consumer perceived quality. Therefore, this paper analyzes the quality of these cues by Factor dimensionality reduction to extract a small number of common factors which represent a large number of quality cues. Use analysis of variance to carry on difference analysis among the extracted common factor and the attributes of respondents' gender, age, household type and education background.

\section{Data Sources}

This paper uses field surveys, mailed questionnaires etc to collect data. The survey at the beginning from June 2013 and at the end of November, according to the administrative division, obtaining data in $\mathrm{Fu}$ Zhou, Long Yan ,Nan An, Quan Zhou, San Ming, Zhang zhou Six citys, Fu Jian Province. After screening, excluding in which answer exactly the same in the second part, 918 valid questionnaires are obtained.

\section{ANALYSIS RESULTS}

This paper uses statistical analysis methods of sample statistics, sample description, factor analysis, difference analysis to cope with survey data by SPSS 19.0.

\section{Survey data description}

From gender view of consumer in the survey, the number of male is 549, accounting for $59.8 \%$, the number of female is 369 , accounting for $40.2 \%$. The survey covers all ages of adults, in which consist of two high proportion age groups--21 to 35 and 36 to 50, the number of them are 292 and 274, and account for $31.8 \%$ and $29.8 \%$ respectively. On the one hand, consumers of those two age groups are the backbone of the family who need to obtain animal products higher frequently and more quantity. On the other hand, residents in these age group more likely to accept the questionnaires. In addition, the group aged 20 and below, with the number of 184 , accounts for $20 \%$. And the group aged at 51 to 65 add up to 157 , accounts for $17.1 \%$, the group aged 66 and above, only 11 persons, accounts for $1.2 \%$.From the view of household type, there are 578 rural people, accounting for $63 \%$ and 340 urban 
people, accounting for $37 \%$.From the statistic of education background, the number of primary and lower is 124, accounting for $13.5 \%$, the number of junior school is 296,accounting for
$32.8 \%$, the number of senior school is 195 , accounting for $21 \%$, the number of bachelor degrees is 301 , accounting for $32.8 \%$, the number of master degrees is 2 , only accounting for $0.2 \%$.

TABLE 1: Characteristics of the survey sample

\begin{tabular}{|llll|}
\hline Category & Sample classification & N & $\%$ \\
\hline \multirow{2}{*}{ gender } & female & 369 & 40.2 \\
& male & 549 & 59.8 \\
age & 20 and below & 184 & 20.0 \\
& 21 to 35 & 292 & 31.8 \\
\multirow{4}{*}{ Household type } & 36 to 50 & 274 & 29.8 \\
& 51 to 65 & 157 & 17.1 \\
& 66 and above & 11 & 1.2 \\
Education background & rural & 578 & 63.0 \\
& urban & 340 & 37.0 \\
& primary and lower & 124 & 13.5 \\
& junior school & 296 & 32.2 \\
Data source: Statistical analysis based on questionnaires & 195 & 21.2 \\
& senior school & 301 & 32.8 \\
\hline
\end{tabular}

\section{Factor analysis of animal product consumer perceived quality}

Before factor analysis, test the sample by KMO and Bartlett (Table 2). As table 2 shown, KMO statistic value is 0.852 , which indicates a high degree of overlap information between variables, suitable for factor analysis. Bartlett's test of sphericity results shows that chi-squared approximation statistic value is 3676.909, significant probability of 0.000 , less than 0.001 , which illustrate data is relevant, the correlation matrix is not an identity matrix, factor analysis can be performed.

TABLE 2: KMO and Bartlett's test

\begin{tabular}{|crr|}
\hline Kaiser-Meyer-Olkin Measure of Sampling Adequacy & .852 \\
\hline & Approx.Chi-Square & 3676.909 \\
Bartlett 's Test of Sphericity & df & 120 \\
& Sig. & .000 \\
\hline
\end{tabular}

Data source: Statistical analysis based on questionnaires

Use principal component analysis, orthogonal rotation maximum variance method to extract factors whose characteristic root values are greater than 0.9 , and the cumulative explain variances are greater than $60 \%$, and finally choice five common factors. The rotated factor load data in Table 3.

Factor analysis results show that the factors which can affect consumer perceived quality of animal product can be simplified to five common factors explaining $60.216 \%$ of the total cumulative variance. The first factor, characteristic root4.649, explaining $29.056 \%$ of the total variance, includes four quality cuescatching season, cold chain distribution, places to buy, compensation mechanism, which mainly reflecting consumer's awareness of animal products purchasing channels, therefore it can be named store image. The second factor, characteristic root 1.588 ,explaining $9.925 \%$ of the total variance, includes four quality cuesbrand, drug residues, origin certification, date of manufacture, which mainly reflecting consumer's awareness of animal products safety, therefore it can be named brand quality. The third factor, characteristic root1.400, explaining 
$8.752 \%$ of the total cumulative variance, includes three cues-cutting, packaging, the level of fat, which mainly reflecting consumer's awareness of animal products processing, therefore it can be named processing convenient. The fourth factor, characteristic root 1.047, explaining $6.546 \%$ of the total variance, includes three quality cues- color, price and last time buying experience, which mainly reflecting consumer's intuition of animal products quality, therefore it can be named experience cognition. The fifth factor, characteristic root 0.950 , explaining $5.937 \%$ of the total cumulative variance, includes two quality cues-marbling and $\mathrm{PH}$ value, which mainly reflecting consumer awareness of animal products physical attributes, therefore it can be named physical properties.

TABLE 3 Ingredients rotation matrix

\begin{tabular}{|lccccc|}
\hline & Factor1 & Facotr2 & Factor3 & Factor4 & Factor5 \\
\hline Color & 0.063 & 0.089 & 0.326 & $\mathbf{0 . 5 6 1}$ & 0.138 \\
Cutting & 0.115 & 0.004 & $\mathbf{0 . 7 4 5}$ & 0.025 & 0.214 \\
Packaging & 0.117 & 0.167 & $\mathbf{0 . 7 7 2}$ & 0.065 & -0.059 \\
the level of fat & 0.098 & 0.072 & $\mathbf{0 . 5 7 2}$ & 0.381 & 0.133 \\
Marbling & 0.045 & 0.016 & 0.421 & 0.076 & $\mathbf{0 . 6 7 3}$ \\
PH value & 0.259 & 0.166 & -0.002 & 0.115 & $\mathbf{0 . 7 4 7}$ \\
Price & -0.327 & 0.269 & 0.156 & $\mathbf{0 . 5 7 2}$ & 0.163 \\
Brand & 0.019 & $\mathbf{0 . 7 2 3}$ & 0.115 & 0.032 & 0.241 \\
Drug residues & 0.225 & $\mathbf{0 . 5 7}$ & 0.058 & 0.379 & -0.06 \\
Origin certification & 0.368 & $\mathbf{0 . 6 4 9}$ & 0.052 & -0.066 & 0.294 \\
Production date & 0.141 & $\mathbf{0 . 6 6}$ & 0.039 & 0.348 & -0.19 \\
Catching season & $\mathbf{0 . 5 6 6}$ & 0.413 & 0.255 & -0.063 & 0.081 \\
Cold chain distribution & $\mathbf{0 . 7 1 3}$ & 0.244 & 0.265 & 0.033 & 0.155 \\
Purchase options & $\mathbf{0 . 5 5 9}$ & 0.316 & 0.183 & 0.429 & -0.134 \\
Payment mechanisms & $\mathbf{0 . 7 5 1}$ & 0.031 & -0.007 & 0.202 & 0.245 \\
Buying experience & 0.35 & 0.036 & -0.068 & $\mathbf{0 . 7 0 6}$ & 0.016 \\
\hline Eigenvalues & 4.649 & 1.588 & 1.4 & 1.047 & 0.95 \\
\% of Variance & 29.056 & 9.925 & 8.752 & 6.546 & 5.937 \\
\% of Cumulative & 29.056 & 38.981 & 47.734 & 54.28 & 60.216 \\
\hline
\end{tabular}

Data source: Statistical analysis based on questionnaire

\section{Difference analysis of personal attributes' influence on animal products consumer perceived quality}

Difference analysis for gender's influence on animal products consumer perceived quality. Independent samples t-test results show that the factor of gender has a significant influence on resident's consumer perceived quality of animal product. Specifically, gender has a significant influence on store image and brand quality, but non-significant on ease of processing, intuitive cognition and physical properties. The possible reason is that the division of men and women in the family tends to weaken with the social development, during in participating in the purchase, cooking and processing of animal products together, the perception, for processing, intuition and physical performance, presents convergence.

Difference analysis for age's influence on animal products consumer perceived quality. ANOVA results show that residents in different ages had significant difference on animal products consumer perceived quality. The age factor has a significant influence on store image, brand quality and intuitive cognition, but nonsignificant on processing and physical properties. For parried comparison of variable's means, the results show that the cognition in different ages is difference. The group of 20 years old and younger, who believe that store image and brand quality are more important, compared with the group aged between 21 and 65 . The group of 51 years old and younger 
believe that intuitive cognition are more important, compared with the group aged between 51 and 65 .

Difference analysis for household type's influence on animal products consumer perceived quality. Independent samples t-test results show that the factor of household has a significant influence on resident's consumer perceived quality of animal products. Specifically, except the factor named processing, store image, brand quality, intuitive cognition and physical properties significant influenced.

Urban people believe that store image, brand quality, and intuitive cognition are more important, but rural people believe that physical properties such as marbling are important basis to judge animal products consumer perceived quality.

Difference analysis for education background's influence on animal products consumer perceived quality. ANOVA results show that education background had influence on all five factors-store image, brand quality, processing, intuitive cognition and physical properties. The results, parried comparison of variable's means, show that primary and lower believe that store image and brand quality were not important, at the same time, processing, intuitive cognition and physical properties are more important, compared with the junior, the senior and the bachelor consumers.

TABLE 4: The results for difference analysis of personal attributes' influence on animal products consumer perceived quality

\begin{tabular}{|ccccccccc|}
\hline & \multicolumn{2}{c}{ T-value } & \multicolumn{2}{c}{ F-value } & \multicolumn{4}{c|}{ Sig. } \\
\cline { 2 - 9 } & gender & household & age & education & gender & household & age & education \\
\cline { 2 - 9 } Store image & 5.488 & -4.349 & 13.801 & 8.388 & $\mathbf{0 . 0 0 0}$ & $\mathbf{0 . 0 0 0}$ & $\mathbf{0 . 0 0 0}$ & $\mathbf{0 . 0 0 0}$ \\
Brand quality & 3.117 & -3.823 & 5.961 & 5.218 & $\mathbf{0 . 0 0 2}$ & $\mathbf{0 . 0 0 0}$ & $\mathbf{0 . 0 0 0}$ & $\mathbf{0 . 0 0 0}$ \\
processing & -0.091 & 0.629 & 0.201 & 2.869 & 0.928 & 0.529 & 0.938 & $\mathbf{0 . 0 2 2}$ \\
intuitive cognition & -0.289 & -3.838 & 5.335 & 12.584 & 0.773 & $\mathbf{0 . 0 0 0}$ & $\mathbf{0 . 0 0 0}$ & $\mathbf{0 . 0 0 0}$ \\
physical properties & -1.823 & 4.759 & 1.072 & 4.820 & 0.069 & $\mathbf{0 . 0 0 0}$ & 0.369 & $\mathbf{0 . 0 0 1}$ \\
\hline Data source: Statistical analysis based on questionnaire & & & & & &
\end{tabular}

Data source: Statistical analysis based on questionnaire

\section{CONCLUSIONS}

Analysis of the survey data can draw the following main conclusions: (1) the perceived quality of animal product is a comprehensive evaluation results, through various quality cues durin9g the purchase process, have a direct guidance for consumers' buying behaviours.(2)consumers in Fujian Province are more concerned about the perceived quality of animal products. And those cues, which consist of price, pesticide residues, production date, and the last place to buy , and consumer experience, are more important on the perceived quality of animal products.(3)Store image, brand quality, processing, intuitive experience and physical properties, such five dimensions are suggestion to judge the perceived quality of animal
products.(4)Personal attributes consisting of gender ,age ,household type and education background have a significant effect on perceived quality of animal products.

\section{REFERENCES}

[1]. Olson,J.C.; Jacoby, J. Cue utilization in the quality perception process. M.VenkateSan. Proceedings ofthe Third Annual Conference of the Association of Consumer Research, ed. Association for Consumer Research, Iowa City, pp.167-179,1972.

[2]. Riesz. Journal of Marketing Research. 1(2),pp.259$262,1971$.

[3]. Zeithaml,V.A. Consumer perceptions of price, quality,and value: Ameans-end model and synthesis of evidence.Marketing . 52,pp.2-22,1988.

[4]. Cox D F.The Measurement of Information Value: A Study in Consumer DecisionMaking.W S Decker.Emerging Concepts in 
marketing.Chicago:American Marketing Association, 1962.

[5]. Steenkamp, J.-B.E.M.\&VanTriJp,H.C.M. Quality guidance:a consumer-based approach forproduct quality improvement.In Marketing Thought and Practice in the 1990s.eds G.J.Avlonitis,N.K.Papavasiliou\& A. G. Kouremenos. Conference Proceedings XVIII Annual Conference of theEuropean Marketing Academy,Athens,pp.717-36, 1989.

[6]. Rao A R,Monroe K B.The Effect of Price,Brand Name and Store Nameon Buyer's Perceptions of Product Quality:An Integrative Review. Journal of Marketing Research, 26,pp.351-357, 1989.

[7]. Klaus Gunter Grunert, Hanne Hartvig Larsen, Allan Baadsgaard, et al. Market Orintation in Food and Agriculture.Springer,1995.
[8]. Bredahl,L.Cueutilisation and quality perception with regard to branded beef.Food Quality and Preference.15,pp.65-75, 2001.

[9]. Renee Kim.Japaneseconsumers'use of extrinsic and intrinsic cues ti mitigate risky food choices.International Journal of Consumer Studies,32(1),pp.49-58,2008.

[10]. Fu guogun, TongXueying. How brand, price and country of origin influence consumers'purchase choices.JOURNAL OF MANAGEMENT SCIENCES IN CHINA, 6(6),pp.19-25,2003.

[11]. Wang Haizhang, Wang Jingxue, He Yun .The Suggestive Effect of Brand Naming, County-of-origin, Price on Quality Perception and Purchase Wiilingness: An Empirical Study in China. NANKAT RiJSTNRSSRRVTRW.10(6),pp.19-25,2007. 